\title{
Colorectal cancer in India: controversies, enigmas and primary prevention
}

\author{
K. M. Mohandas
}

Received: 14 December 2010 / Accepted: 14 December 2010/Published online: 11 January 2011

(C) Indian Society of Gastroenterology 2011

\begin{abstract}
One swears by whole meal bread, one by sour milk; vegetarianism is the only road to salvation of some, others insist not only on vegetables alone, but on eating those raw. At one time the only thing that matters is calories; at another time they are crazy about vitamins and roughage. The scientific truth may be put quite briefly; eat moderately, have an ordinary mixed diet and don't worry. Sir Robert Hutchinson, in Newcastle Medical Journal 1932, Vol 12
\end{abstract}

Colorectal cancer (CRC) is the third most common cancer in men $(663,000$ cases, $10.0 \%$ of the total cancers) and the second in women $(570,000$ cases, $9.4 \%$ of the total cases) worldwide [1]. Incidence rates of CRC vary 10 -fold in both sexes worldwide, the highest rates being estimated in Australia/New Zealand and Western Europe, the lowest in Africa (except Southern Africa) and South-Central Asia [1]. Within Asia, the incidence rates of CRC vary widely and are uniformly low in all south Asian countries and high in all developed Asian countries (Table 1). The burden of $\mathrm{CRC}$ has risen rapidly in some economically developed Asian countries like Japan, South Korea and Singapore $[1,2]$. Fortunately, the age adjusted incidence rates of CRC in all the Indian cancer registries are very close to the lowest rates in the world [2]. Hospital based and population based data also show that the incidence rates for rectal cancer is higher than colon cancer in all parts of India $[2,3]$. Limited data from the rural population based registries indicate that the incidence rates of colon cancer is very low in the rural settings. However the incidence

K. M. Mohandas $(\bowtie)$

Room 24, Department of Digestive Diseases and Nutrition,

Tata Memorial Hospital,

Mumbai 400 012, India

e-mail: mohandaskm@gmail.com rates of rectal cancer is disproportionately higher in rural India [2-4]. The intra country variation of the incidence rates of CRC across India is limited, unlike the striking north south differences in the incidence rates of stomach cancer and gall bladder cancer [3, 4]. Population based time trend studies show a rising trend in the incidence of CRC in India [5]. Worrisome is the finding that the incidence rates of CRC in Indian immigrants to the United Kingdom and USA are much higher, suggesting that life styles and dietary habits are important in the causation of the CRC [6-8]. This also means that with economic transition from a low income to middle income economy, there will be a big increase in the burden of CRC in India.

Decades of expensive and replicating research studies have had little impact on primary prevention of CRC. In high incidence countries screening for adenomas and early CRC using fecal occult blood, flexible sigmoidoscopy and colonoscopy has helped to prevent $\mathrm{CRC}$ and reduce mortality from CRC [9]. The causes for CRC range from germline mutations of high penetrance genes such as the adenomatous polyposis coli genes to a completely environmental risk factor such as excess body mass index at the other end. About $6 \%$ of all CRC are caused by the inheritance of muted genes with high penetrance [9]. Life style and dietary factors are responsible for over two thirds of all CRC [9]. The role of environment and life style is seen even in families inheriting muted high penetrance genes. The sites of cancer in families with hereditary nonpolyposis colorectal cancer (HNPCC) have mirrored the sporadic cancer incidence [10]. In Asian countries such as Korea and Japan where stomach cancer is the leading sporadic cancer, the HNPCC cancer spectrum includes considerably higher number of stomach cancer [11]. There is a hot pursuit to identify the genes causing CRC, in the post-genomic era. In a recent meta-analysis, three genome 
Table 1 Incidence rates of colorectal cancer in Asia

\begin{tabular}{|c|c|c|}
\hline \multirow[t]{2}{*}{ Country } & \multicolumn{2}{|c|}{ Incidence rates per $100,000^{\mathrm{a}}$} \\
\hline & Male & Female \\
\hline India & 4.3 & 3.4 \\
\hline Yemen & 4.3 & 4.6 \\
\hline Bangladesh & 4.5 & 4.0 \\
\hline Egypt & 4.6 & 4.3 \\
\hline Pakistan & 4.9 & 4.2 \\
\hline Iraq & 5.2 & 4.0 \\
\hline Nepal & 5.3 & 4.8 \\
\hline Syrian Arab Republic & 6.5 & 4.9 \\
\hline Afghanistan & 6.9 & 7.0 \\
\hline Oman & 7.3 & 6.8 \\
\hline United Arab Emirates & 7.3 & 8.4 \\
\hline Sri Lanka & 7.5 & 5.8 \\
\hline Bhutan & 7.9 & 4.4 \\
\hline Islamic Republic of Iran & 8.7 & 6.4 \\
\hline Qatar & 10.5 & 11.8 \\
\hline Kuwait & 11.8 & 13.4 \\
\hline Myanmar & 12.2 & 12.0 \\
\hline Bahrain & 12.4 & 7.8 \\
\hline Turkey & 13.2 & 9.1 \\
\hline Saudi Arabia & 14.3 & 9.8 \\
\hline Jordan & 15.2 & 11.9 \\
\hline China & 16.3 & 12.2 \\
\hline Indonesia & 19.1 & 15.6 \\
\hline Malaysia & 19.6 & 15.5 \\
\hline Russian Federation & 29.0 & 21.2 \\
\hline United States of America & 34.1 & 25.0 \\
\hline United Kingdom & 36.2 & 23.5 \\
\hline Singapore & 41.6 & 28.3 \\
\hline Japan & 41.7 & 22.8 \\
\hline Israel & 41.7 & 22.8 \\
\hline Republic of Korea & 46.9 & 25.8 \\
\hline
\end{tabular}

${ }^{a}$ Age adjusted rates for world standard population

Data from reference 1 website

wide association studies from the UK were combined to include 3,334 affected individuals (cases) and 4,628 controls, to be followed by multiple validation analyses including a 18,095 cases and 20,197 controls [12]. This meta-analysis identified associations at four new CRC risk loci: $1 \mathrm{q} 41$ (rs6691170 and rs6687758), 3q26.2 (rs10936599) and 12q13.13 (rs11169552 rs7136702) and 20q13.33 (rs4925386) [12]. However, more studies are needed to clarify the role of gene environmental interactions in the development of CRC.

Epidemiological studies evaluating the role of life style factors and dietary factors in the causation of CRC have had a fair share of controversies. It all started in 1974, when the British Medical Journal published an editorial titled 'Diet and Colonic Cancer' supporting the hypothesis of Mr. Dennis Burkitt in Africa [13, 14]. In the winter of 1974, Dr. S L Malhotra (of Indian Railways from Calcutta) wrote to the editor of BMJ challenging the originality of Burkitt's hypothesis [15]. He wrote: Sir, in your leading article, "Diet and Colonic Cancer" (2 March, p. 339), you credited Mr. Denis P. Burkitt for the thesis "that diet and fecal constituents are important in the aetiology of cancer of the large bowel," which he attributes to "the low-residue diet of the West, high in refined carbohydrates and low in fibre." This has obviously happened because Burkitt in his article did not even refer to my work, ${ }^{16}$ published much earlier than his, let alone give me due credit for this thesis. Allow me, therefore, to quote from my article [16], not only to establish priority but, even more important, to draw attention to the explanation why diets rich in cellulose and vegetable fibers are protective. He concluded that "perhaps this may lead to additional information which could go a long way to prevent colonic cancer" [16].

Dr. Malhotra's work published nearly a decade before Mr. Burkitt's paper was forgotten. The dietary fiber theory of Mr. Burkitt spawned thousands of case-control, cohort and randomized intervention trials over the next three decades. As it happens with good scientific research practises, almost all the large studies with designs to minimize bias and confounding failed to provide consistent results or substantial reduction in $\mathrm{CRC}$ with diet high in fruits and vegetables [1723]. The first credible report showing no protective effect of a vegetarian diet against CRC was a meta-analysis of 5 prospective studies of vegetarians living in Western countries [17]. A more recent study of British vegetarians found a $12 \%$ non significant increase in CRC among the vegetarians in comparison to meat eaters [18]. The multi European EPIC study which followed 142,605 men and 335,873 women for a median of 8.7 years showed a small inverse association between intake of total fruits and vegetables and CRC risk in non tobacco users [19]. This study also reported a $20 \%$ increase risk (non significant) for CRC in current smokers with high fruit and vegetable consumption [19]. Metaanalysis of various prospective cohort studies have also not helped to clarify the ambiguity. In the largest pooled analysis of 14 studies with 756,217 subjects who were followed up for 6 to 20 years, fruit and/or vegetable intakes were not strongly associated with CRC risk overall but may be associated with a lower risk of distal colon cancer [20]. Some of these confusing results from various large prospective studies and their meta-analysis are due to residual confounding that can only be eliminated with randomized controlled trials. From this perspective, the billion dollar Women's Health Initiative randomized trial also failed to reduce $\mathrm{CRC}$ in participants randomized to low fat, high fruits and vegetables arm [21]. 
Higher consumption of red meat and processed meat had been implicated in the causation of CRC for several decades. There are numerous large well-designed prospective studies that have looked into this. One of the earlier meta-analysis of 15 prospective studies reported that high consumption of red meat and of processed meat is associated with an increased risk of CRC [22]. This metaanalysis projected summary RR of 1.28 (95\% $\mathrm{CI}=1.18-$ 1.39 ) for an increase of $120 \mathrm{~g} /$ day of red meat and 1.09 (95\% CI $=1.05-1.13)$ for an increase of $30 \mathrm{~g} /$ day of processed meat. The United Kingdom (UK) Dietary Cohort Consortium examined the associations of meat, poultry and fish intakes with CRC risk by using individual data from prospective food diaries, and pooling seven prospective studies from the UK [23]. There was little evidence of association between the food groups examined and risk for colorectal cancer: Odds ratios (95\% confidence intervals) for a $50 \mathrm{~g}$ /day increase were $1.01(0.84-1.22)$ for red meat and $0.88(0.68-1.15)$ for processed meat [23]. Two other meta-analysis published recently have failed to show any significant association between red meat or processed meat and CRC [24, 25]. A very recent systematic review of diet and cancer by Professor Key from Oxford University created a lot of media headlines because of the conclusion that overall, the data do not show a clear association between fruits and vegetables and the risk for colorectal cancer, although they are compatible with a small reduction in risk [26]. There have also been several prospective and interventional studies evaluating the role of micronutrients consumption in the causation of CRC [27-30]. In general these meta-analysis report that vitamin $\mathrm{D}$, vitamin $\mathrm{B}$ and folic acid are associated with reduced risk of CRC.

The article by Javid et al. in the current issue of the Journal reports that the incidence rates for CRC in Kashmir (an area with distinct culture and food habits) are enigmatically as low as in other parts of India [31]. This study also found that the CRC in Kashmir are more common in men, in older individuals and the urban regions. Like the rest of India, rectal cancer was more common than colon cancer. The authors did try their best to follow good cancer registration processes and looked for case finding in all possible areas where CRC is diagnosed and treated in Kashmir. They also looked at the death certificates to completely capture the incidence. Nonetheless, the case finding is likely to have missed some CRC patients on several grounds with a possibility of under registration. First, the patients with CRC may travel to other places for diagnosis and treatment of cancer. We see several Kashmiri patients coming to Tata Memorial Hospital, Mumbai for treatment. Many go to other referral hospitals in New Delhi. These patients can be missed easily. Second, unlike patients with upper GI cancers, the patients with CRC live for several years even with metastatic disease. Intensive search and review of death certificates for 1 year is not sufficient to find all cases. Thirdly, information about the site and type of cancer is often missing in the death certificates. Barring a few metropolitan regions most parts of India do not have a mandatory medical certification of deaths. As a result some cancers are missed. Finally, many CRC patients present as liver metastasis from unknown primary. In the absence of a complete work up including a colonoscopy the large bowel origin of these cancers are missed. This is helped by a tendency to minimize investigations and treatment of elderly cancer patients with multiple liver metastases. Conversely, there is a small possibility of over registration as the data collection was done only for 1 year with the possibility of including prevalent cases from previous year. The incidence CRC in Kashmir is still very low after assuming that $20 \%$ of all CRC may be missed due to the above limitations. These rates are also lower than those reported from Ahmedabad where $90 \%$ of the people are vegetarians and the per capita alcohol consumption is one of the lowest in India due to prohibition [7]. This article thus provides some more ecological evidence that CRC rates can be low in a non-vegetarian communities [26]. Lower CRC incidence is reported from several Middle East Asian countries (Table 1) [1]. The ecological variation in the incidence of CRC in Asia is more closely related to the national per capita income.

While the incidence rate of CRC in native Indians has been rising slowly over many decades, the incidence of CRC in immigrant Indians living in the UK and USA have raised rapidly. The absolute burden of $\mathrm{CRC}$ has also increased in India during last three decades. During a 32-year period (1941-1972), 555 cases of CRC were recorded at the Tata Memorial Hospital, Mumbai [32]. In contrast a total of 560 cases of CRC were treated at the same institution in 2006 alone. This rise in case loads in our hospital is primarily due to the increase in the Indian population combined with ageing of the Indian population. However, economic transition does make Indians susceptible to CRC. Previous data from our hospital does show that some of the socioeconomically well off Indians like the Parsis (Zoroastrians) in Mumbai had high incidence of CRC even 30 years ago [32]. Ali et al. stated that the pattern of cancer incidence observed in British Indians provides an indication of what may happen in the future in some parts of India (particularly urban areas) as it undergoes its own rapid epidemiological transition [7].

Finding the factors responsible for the low incidence of $\mathrm{CRC}$ in India will help in primary prevention of CRC. For decades it has been believed that the predominantly vegetarian diet with high fiber and low meat intake is responsible for the low CRC incidence in India. All the large prospective studies and meta-analysis suggest that other causative possibilities need to be examined. Plausible 
mechanisms include consumption of fewer calories and alcohol by vegetarians as well as diet-induced variations in the intestinal immunity modulated by the gut microbiota [33]. In the absence of robust data from controlled clinical trials, the general principles for cancer prevention should have a holistic approach with emphasis on a healthy diet and health promotion activities. We need to address the rapidly increasing problem of vitamin D deficiency among rural and urban Indians [34]. Meta-analysis of several studies confirms the protective role of physical activity in CRC prevention in both men and women [35]. Consumption of moderate amounts of fruit and vegetables sufficient to prevent micronutrient deficiencies, avoiding excess weight gain by balancing energy intake and energy expenditure with physical activity and avoiding tobacco in all forms will remain the ultimate means to prevent several cancers and contribute to health gains in our community.

\section{References}

1. Ferlay J, Shin HR, Bray F, Forman D, Mathers C, Parkin DM. Estimates of worldwide burden of cancer in 2008: GLOBOCAN 2008. Int J Cancer. 2010;127:2893-917.

2. Curado MP, Edwards B, Shin HR, et al. (Eds). Cancer Incidence in Five Continents, Volume IX. IARC Scientific Publication, No 160 IARC, Lyon 2007.

3. National Cancer Registry Programme. Accessed at: http://www. icmr.nic.in/ncrp/cancer_reg.htm on November 4, 2010.

4. Swaminathan R, Selvakumaran R, Esmy PO, et al. Cancer pattern and survival in a rural district in South India. Cancer Epidemiol. 2009;33:325-31.

5. Yeole BB. Trends in cancer incidence in esophagus, stomach, colon, rectum and liver in males in India. Asian Pac J Cancer Prev. 2008;9:97-100.

6. Rastogi T, Devesa S, Mangtani P, et al. Cancer incidence rates among South Asians in four geographic regions: India, Singapore, UK and US. Int J Epidemiol. 2008;37:147-60.

7. Ali R, Barnes I, Kan SW, Beral V. Cancer incidence in British Indians and British whites in Leicester, 2001-2006. Br J Cancer. 2010;103:143-8.

8. Miller AB, Chu KC, Hankey BF, Ries LAG. Cancer incidence and mortality patterns among specific Asian and Pacific Islander populations in the U.S. Cancer Causes Control. 2008;19:227-56.

9. Cunningham D, Atkin W, Lenz HJ, et al. Colorectal cancer. Lancet. 2010;375:1030-47.

10. Douglas JA, Gruber SB, Meister KA, et al. History and molecular genetics of lynch syndrome in family G: a century later. JAMA. 2005;294:2195-202.

11. Park YJ, Shin KH, Park JG. Risk of gastric cancer in hereditary nonpolyposis colorectal cancer in Korea. Clin Cancer Res. 2000;6:2994-8.

12. Houlston RS, Cheadle J, Dobbins SE, et al. Meta-analysis of three genome-wide association studies identifies susceptibility loci for colorectal cancer at 1q41,3q26.2, 12q13.13 and 20q13.33. Nat Genet. 2010;42:973-7.

13. Annonymous. Diet and colonic cancer. Editorial. $\mathrm{Br}$ Med J. 1974;1:339-40.
14. Burkitt DP. Epidemiology of cancer of the colon and rectum. Cancer. 1971;28:3-13.

15. Malhotra SL. Diet and colonic cancer. Br Med J. 1974;4:532.

16. Malhotra SL. Geographical distribution of gastrointestinal cancers in India with special reference to causation. Gut. 1967;8: 361-72.

17. Key TJ, Fraser GE, Thorogood M, et al. Mortality in vegetarians and nonvegetarians: detailed findings from a collaborative analysis of 5 prospective studies. Am J Clin Nutr. 1999;70 suppl:516S-24.

18. Key TJ, Appleby PN, Spencer EA, et al. Cancer incidence in British vegetarians. Br J Cancer. 2009;101:192-7.

19. van Duijnhoven FJ, Bueno-De-Mesquita HB, Ferrari P, et al. Fruit, vegetables, and colorectal cancer risk: the European Prospective Investigation into Cancer and Nutrition. Am J Clin Nutr. 2009;89:1441-52.

20. Koushik A, Hunter DJ, Spiegelman D, et al. Fruits, vegetables, and colon cancer risk in a pooled analysis of 14 cohort studies. J Natl Cancer Inst. 2007;99:1471-83.

21. Beresford SAA, Johnson KC, Ritenbaugh C, et al. Low-fat dietary pattern and risk of colorectal cancer. The Women's Health Initiative Randomized Controlled Dietary Modification Trial. JAMA. 2006;295:643-54.

22. Larsson SC, Wolk A. Meat consumption and risk of colorectal cancer: a meta-analysis of prospective studies. Int $\mathrm{J}$ Cancer. 2006;119:2657-64.

23. Spencer EA, Key TJ, Appleby PN, et al. Meat, poultry and fish and risk of colorectal cancer: pooled analysis of data from the UK dietary cohort consortium. Cancer Causes Control. 2010;21: $1417-25$.

24. Alexander DD, Miller AJ, Cushing CA, Lowe KA. Processed meat and colorectal cancer: a quantitative review of prospective epidemiologic studies. Eur J Cancer Prev. 2010;19:328-41.

25. Alexander DD, Cushing CA. Red meat and colorectal cancer: a critical summary of prospective epidemiologic studies. Obes Rev. $2010 \mathrm{Jul}$ 21. [Epub ahead of print].

26. Key TJ. Fruit and vegetables and cancer risk. Br J Cancer. 2010 Nov 30. [Epub ahead of print].

27. Larsson SC, Orsini N, Wolk A. Vitamin B6 and risk of colorectal cancer: a meta-analysis of prospective studies. JAMA. 2010;303: 1077-83.

28. Kim DH, Smith-Warner SA, Spiegelman D, et al. Pooled analyses of 13 prospective cohort studies on folate intake and colon cancer. Cancer Causes Control. 2010;21:1919-30.

29. Park Y, Spiegelman D, Hunter DJ, et al. Intakes of vitamins A, C, and $\mathrm{E}$ and use of multiple vitamin supplements and risk of colon cancer: a pooled analysis of prospective cohort studies. Cancer Causes Control. 2010;21:1745-57.

30. Yin L, Grandi N, Raum E, Haug U, Arndt V, Brenner H. Metaanalysis: longitudinal studies of serum vitamin $\mathrm{D}$ and colorectal cancer risk. Aliment Pharmacol Ther. 2009;30:113-25.

31. Javid G, Zargar SA, Rather S, et al. Incidence of colorectal cancer in Kashmir Valley, India. Indian J Gastroenterol. 2011; doi:10.1007/s12664-010-0071-7.

32. Jussawalla DJ, Gangadharan P. Cancer of the colon: 32 years of experience in Bombay, India. J Surg Oncol. 1977;9:607-22.

33. Cerf-Bensussan N, Gaboriau-Routhiau V. The immune system and the gut microbiota: friends or foes? Nat Rev Immunol. 2010;10:735-44.

34. Babu US, Calvo MS. Modern India and the vitamin D dilemma: evidence for the need of a national food fortification program. Mol Nutr Food Res. 2010;54:1134-47.

35. Wolin KY, Yan Y, Colditz GA, Lee IM. Physical activity and colon cancer prevention: a meta-analysis. Br J Cancer. 2009;100:611-6. 